\title{
Idiopathic focal segmental glomerulosclerosis and HLA antigens
}

\section{Gerbase-DeLima', A. Pereira-Santos' R. Sesso', J. Temin', E.S. Aragão ${ }^{1}$ and H. Ajzen ${ }^{2}$}

\author{
1Disciplina de Alergia, Imunologia Clínica e Reumatologia, \\ Departamento de Pediatria, and ${ }^{2}$ Disciplina de Nefrologia, \\ Departamento de Medicina, Escola Paulista de Medicina, \\ Universidade Federal de São Paulo, São Paulo, SP, Brasil
}

Correspondence
M. Gerbase-DeLima
Disciplina de Alergia, Imunologia
Clínica e Reumatologia
EPM, UNIFESP
Rua dos Otonis, 725
04025-002 São Paulo, SP
Brasil
Fax: 55 (011) 570-1590
E-mail: ger.dped@epm.br
Research supported by FAPESP and
CNPq.
. . . . . . . . . . . . . . . . . . . . . . . .

Received June 6, 1997

Accepted January 9, 1998

\section{Abstract}

The objective of the present study was to investigate a possible association between HLA class II antigens and idiopathic focal segmental glomerulosclerosis (FSGS). HLA-A, -B, -DR and -DQ antigens were determined in 19 Brazilian patients (16 white subjects and three subjects of Japanese origin) with biopsy-proven FSGS. Comparison of the HLA antigen frequencies between white patients and white local controls showed a significant increase in HLA-DR4 frequency among FSGS patients $(37.7 v s 17.2 \%, \mathrm{P}<0.05)$. In addition, the three patients of Japanese extraction, not included in the statistical analysis, also presented HLA-DR4. In conclusion, our data confirm the association of FSGS with HLA-DR4 previously reported by others, thus providing further evidence for a role of genes of the HLA complex in the susceptibility to this disease.

Idiopathic focal segmental glomerulosclerosis (FSGS) is characterized by the presence of areas of mesangial sclerosis with collapse of the capillary loops in some glomeruli. A common clinical presentation is the nephrotic syndrome that frequently progresses to end-stage renal disease. The etiology, as well as the pathogenetic mechanism of the disease remains unknown. FSGS usually occurs sporadically but recurrent cases within families have been reported (1-3), suggesting a genetic basis for this disease. A few reports on family cases typed for HLA antigens have shown that the patients within each family shared at least one HLA haplotype, although the shared haplotypes were not the same in the different families (4-7). Association studies in which HLA antigen frequencies were compared between unrelated patients and the general population have yielded controversial results. Glicklich et al. (8) found a significant increase in HLA-DR4 frequency both in white and in black American patients, with this association being most striking in patients older than 18 years at the time of diagnosis. Another study on the American population, however, failed to confirm these data (9). Two other studies, one on the Australian population (7) and the other on the Brazilian population (10), also did not disclose significant associations. The purpose of the present communication was to report data of an investigation of HLA and FSGS conducted on Brazilian patients, the results of which suggest an association with HLA-DR4, in 
agreement with the findings reported by Glicklich et al. (8).

Our series comprised 19 Brazilian patients (16 white subjects and three subjects of Japanese origin) with biopsy-proven FSGS, seen at São Paulo Hospital, Escola Paulista de Medicina, over a three-year period. The criteria for indication of a renal biopsy were proteinuria ( $>0.5 \mathrm{~g} /$ day $)$ or reduced renal function (creatinine clearance $<80 \mathrm{ml} / \mathrm{min}$ ). Kidney tissue was prepared for light and immunofluorescent microscopy by standard techniques. Sections for light microscopy were routinely stained with hematoxylin-eosin, Schiff's periodic acid, trichrome and silver methenamine. A renal biopsy specimen was considered to be appropriate for analysis if it contained at least five glomeruli. The diagnosis of FSGS was made when some glomeruli showed segmental capillary wall collapse with sclerosis and effacement of the capillary lumina. Tubulointerstitial involvement, glomerular hyalinosis and deposition of IgM and/or C3 in the regions of segmental sclerosis were commonly found but were not essential for diagnosis. All patients with evidence of secondary glomerular disease were excluded from this study. Screening for secondary causes of FSGS was carried out on the basis of fasting blood glucose, serum antinuclear antibodies, serum complement (C3, C4 and CH50), hepatitis B surface antigen, HIV, Mansoni schistosomiasis and sickle cell disease. Patients with Alport's syndrome and patients with vesicoureteral reflux were also excluded. Nephrotic syndrome was defined as proteinuria $>3.5 \mathrm{~g} /$ day $/ 1.73 \mathrm{~m}^{2}$ body surface area, associated with serum albumin $<3.0 \mathrm{~g} / \mathrm{dl}$. The sample of white patients comprised eight men and eight women, with a mean age of 27 years (range: 2-64 years) at the time of diagnosis; 10 patients had nephrotic syndrome and six presented only proteinuria. The three Japanese patients (one man and two women) were 28 to 42 years old and all of them had nephrotic syndrome.

HLA-A, -B, -DR (-DR1-9; 52, 53) and -DQ (-DQ1-3) antigens were determined by the standard microlymphocytotoxicity test (11) using commercial sera (Biotest, PelFreez, Brown Deer, WI). The frequencies of HLA antigens observed in the white subjects were compared to those of local ethnically matched controls $(\mathrm{N}=338)$ by the Fisher exact test. Six of the 16 white patients (37.7\%) presented HLA-DR4, whereas the frequency of this antigen in the control group was $17.2 \%$ ( $\mathrm{P}=0.049$, not corrected for the number of comparisons; odds ratio: $2.9 ; 95 \%$ confidence interval: 0.9 to 9.1 ). The three patients of Japanese origin, all of them HLADR4 positive, were not included in the statistical analysis.

In conclusion, our data agree with the findings of Glicklich et al. (8), providing further evidence for an HLA-DR4 associated genetic predisposition to idiopathic focal segmental glomerulosclerosis. It will be interesting to investigate in the future whether this association is stronger with any particular HLA-DR4 allele. 


\section{References}

1. Walker R, Bailey RR, Lynn KL \& Burry AF (1982). Focal glomerulosclerosis - another familial renal disease? New Zealand Medical Journal, 95: 686-688.

2. Kikuta $Y$, Yoshimura $Y$, Saito $T$, Ishihara $T$, Yokoyama S \& Hayashi T (1983). Nephrotic syndrome with diffuse mesangial sclerosis in identical twins. Journal of $\mathrm{Pe}$ diatrics, 102: 586-589.

3. McCurdy FA, Butera PJ \& Wilson R (1987). The familial occurrence of focal segmental glomerular sclerosis. American Journal of Kidney Diseases, 10: 467-469.

4. Trainin EB \& Gomez-Leon G (1983). HLA identity in siblings with focal glomerulosclerosis. International Journal of Pediatric Nephrology, 4: 59-60.
5. Takemura T, Yoshioka K, Okada M, Tsukiyama K, Akano N, Hino S, Murakami K \& Maki S (1993). Focal glomerulosclerosis in a sibling. Nippon Jinzo Gakkai Shi, 35: $875-880$.

6. Tejani A, Nicastri A, Phadke K, Sen D, Adamson O, Dunn I \& Calderon P (1983). Familial focal segmental glomerulosclerosis. International Journal of Pediatric Nephrology, 4: 231-234.

7. Goodman DJ, Clarke B, Hope RN, Miach PJ \& Dawborn JK (1995). Familial focal glomerulosclerosis: a genetic linkage to the HLA locus? American Journal of $\mathrm{Ne}$ phrology, 15: 442-445.

8. Glicklich D, Haskell L \& Weiss RA (1988). Possible genetic predisposition to idio- pathic focal segmental glomerulosclerosis. American Journal of Kidney Diseases, 12: $26-30$

9. Freedman BI, Spray BJ \& Heise ER (1994). HLA associations in IgA nephropathy and in focal segmental glomerulosclerosis. American Journal of Kidney Diseases, 23: 352-357.

10. Kimachi T, Silveira RD, Dantas M, Costa RS \& Donadi EA (1992). Tipagem de antígenos HLA-DR em pacientes portadores de glomerulosclerose segmentar focal (GESF). XVI Congresso Brasileiro de Nefrologia, Rio de Janeiro, 67 (Abstract).

11. Terasaki PI \& McClelland JD (1964). Microdroplet assay of human serum cytotoxins. Nature, 204: 998-1000. 